\title{
Neovascular glaucoma in a pediatric patient with neurofibromatosis type 1: a case report
}

\author{
Sha Liư ${ }^{\dagger}$ Li Ran ${ }^{\dagger}$, Dongmei Qi, Xiaohong Meng ${ }^{*}$ and Tao Yu*
}

\begin{abstract}
Background: To report a case of a young patient with neurofibromatosis type 1 (NF1). Methods: Here we review the treatment administered to a 7-year-old NF1 patient with neovascular glaucoma as the primary diagnosis.

Case presentation: A 7-year-old boy developed visual loss in the right eye associated with periocular pain and ipsilateral headache that had persisted for 1 week. The patient's condition did not improve after treatment with topical or systemic glaucoma medications. Fundus examination of the right eye showed superotemporal retinal vasoproliferative tumors (RVPT). Near-infrared reflectance scans of the left eye's fundus revealed bright patchy regions, scattered across the posterior pole; systemic examination showed café-au-lait spots all over the patient's body. The patient had a clear family history. Genetic testing confirmed NF1. The right eye was treated with intravitreal ranibizumab injection, retinal lesion cryotherapy, and transscleral ciliary body photocoagulation. After treatment, RVPT scarring was observed. The patient's intraocular pressure remained within normal limits.

Conclusions: We report a rare case of neurofibromatosis in a pediatric patient with neovascular glaucoma accompanied by RVPT. We suggest that evaluations of young patients with neovascular glaucoma should include careful attention to the overall condition of the patient and his/her parents, as well as family history. If necessary, NF1 molecular testing should be performed to avoid a missed diagnosis or misdiagnosis.
\end{abstract}

Keywords: Neovascular glaucoma, Retinal vasoproliferative tumors, Neurofibromatosis type 1, Pediatric

\section{Background}

Neurofibromatosis type 1 (NF1) is an autosomal dominant genetic disease, the clinical manifestations of which are diverse, often involving the nervous system, skin, eyes, bones, and other organs. The ocular manifestations of NF1 [1] have been reported to include iris Lisch nodules, optic glioma, retinal abnormalities, congenital glaucoma and so on. In children, neovascular glaucoma is rare, which is more commonly seen in diseases

\footnotetext{
* Correspondence: yt423@sina.com

†Sha Liu and Li Ran contributed equally to this work.

Department of ophthalmology, the first hospital affiliated to Army Medical University (Southwest Hospital), Chongqing 400038, China
}

associated with angiogenic neovascularization, such as retinoblastoma, Coats disease, retinopathy of prematurity, primary hyperplastic persistent vitreous and chronic uveitis [2]. To our knowledge, neovascular glaucoma in NF1, accompanied by retinal vasoproliferative tumor (RVPT) has rarely been reported. Here we report a case of NF1 with RVPT, which resulted in neovascular glaucoma in a pediatric patient. Below we describe the clinical findings and outcomes of the case.

\section{Case presentation}

A 7-year-old boy presented with right eye (RE) pain, decreased vision, and ipsilateral headache for 1 week. The ophthalmologic examination revealed that visual acuity

(c) The Author(s). 2020 Open Access This article is licensed under a Creative Commons Attribution 4.0 International License, which permits use, sharing, adaptation, distribution and reproduction in any medium or format, as long as you give appropriate credit to the original author(s) and the source, provide a link to the Creative Commons licence, and indicate if changes were made. The images or other third party material in this article are included in the article's Creative Commons licence, unless indicated otherwise in a credit line to the material. If material is not included in the article's Creative Commons licence and your intended use is not permitted by statutory regulation or exceeds the permitted use, you will need to obtain permission directly from the copyright holder. To view a copy of this licence, visit http://creativecommons.org/licenses/by/4.0/. The Creative Commons Public Domain Dedication waiver (http://creativecommons.org/publicdomain/zero/1.0/) applies to the data made available in this article, unless otherwise stated in a credit line to the data. 
(VA) was light perception in his RE and 1.0 in the left eye (LE); RE conjunctival hyperemia, corneal edema, iris neovascularization, ectropion uveae and $8 \mathrm{~mm}$ pupil were seen; posterior segment opacity. The intraocular pressure (IOP) was $59 \mathrm{mmHg}$ in RE and $15 \mathrm{mmHg}$ in LE. There were no obvious abnormalities in LE. B-ultrasonography revealed haziness in the vitreous of RE, with no retinal detachment. The child was otherwise healthy and born at full term. The physical examination revealed that the skin of the trunk was scattered with irregular café-au-lait spots (>6) of $0.5-5 \mathrm{~cm}$ in diameter (Fig. 1a). The brain MRI has been performed and the images show there is no presence of optic glioma and other NF1-related change.

Physical examination of the parents revealed numerous irregular café-au-lait spots on the father's trunk. Examination of the father's eyes showed that his best corrected VA was 1.0 with no obvious abnormality. Near-infrared reflectance (NIR) revealed bright patchy regions scattering across the fundus.
After the admission of the patient, the IOP remained over $40 \mathrm{mmHg}$ for 2 days even with intravenous Mannitol $250 \mathrm{ml}$ twice a day, Acetazolamide $250 \mathrm{mg}$ twice a day and Timolol $0.5 \%$ twice a day to lower his IOP. Because of the failure of medical therapy, the third day after admission, intravitreal ranibizumab was injected in the patient's RE. The next day, IOP decreased to $16 \mathrm{mmHg}$; VA was hand motion; corneal edema had resolved; iris neovascularisation disappeared. Fudus findings were unclear margin of the optic disc and abundant yellow-white exudates which were observed at the superotemporal retinal nodular bulge; the vessels could be seen at the margin of the nodule (Fig. 3a, b). These findings suggested a diagnosis of RVPT. The fundus of LE was normal (Fig. 2a). Fluorescein angiography of the fundus showed that the superotemporal retina had a large area of low fluorescence and no abnormal fluorescence was observed in LE (Fig. 2c). NIR revealed bright, patchy regions scattering across the posterior pole of LE (Fig. 2b). a

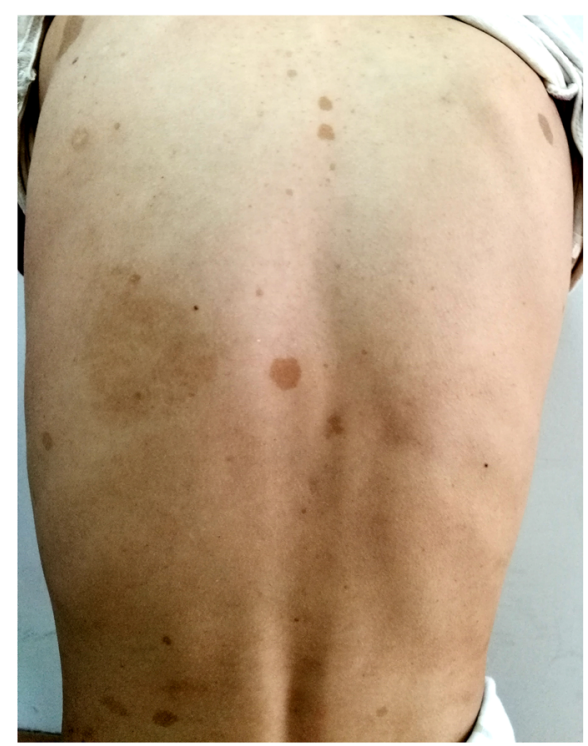

b

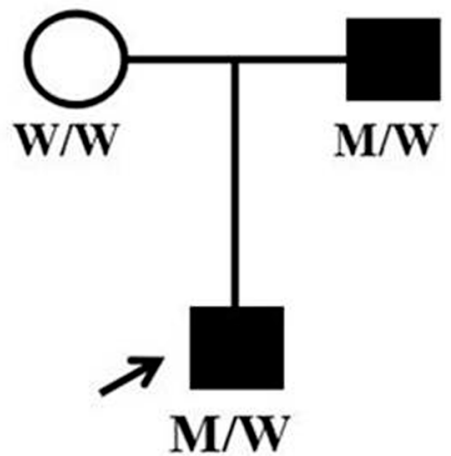

C

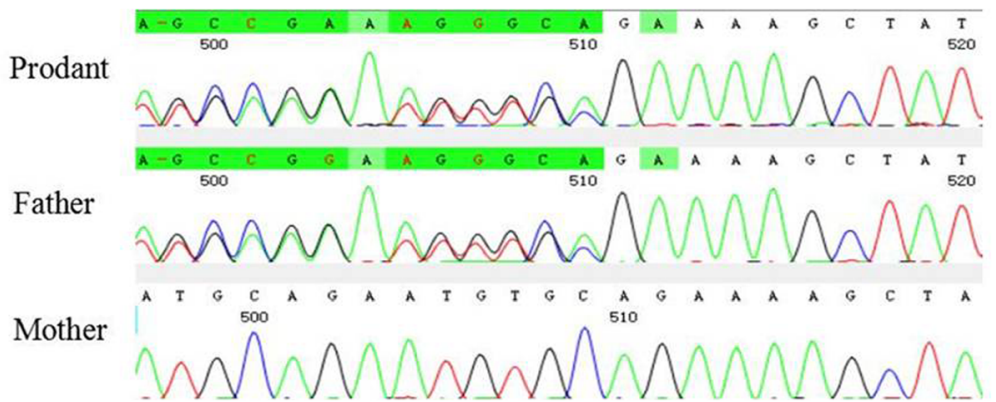

Fig. 1 The skin, pedigree and sequence chromatography of the patient. a. The photo of the patient's trunk, showing irregular café-au-lait spots; b.. Pedigree. W: wild, M:c.738del A. c. One novel sequence change detected in the proband and father with NF1 is shown (right column) compared with corresponding normal sequences (mother) 


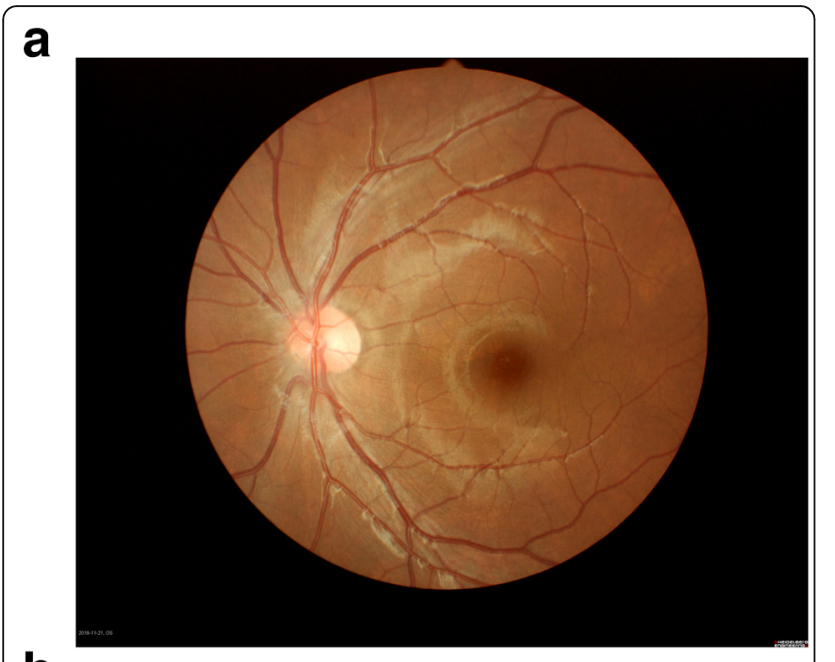

b

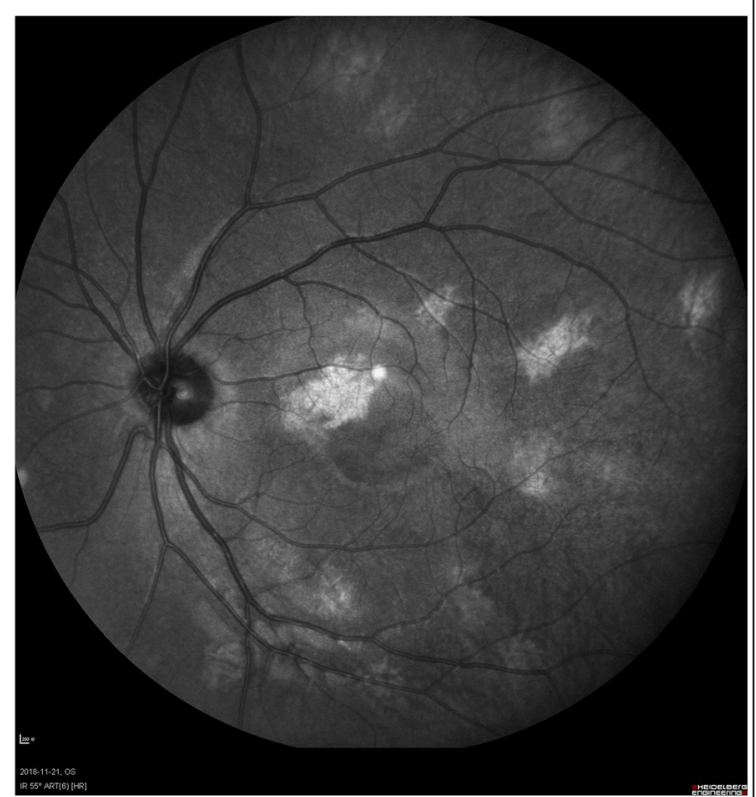

C

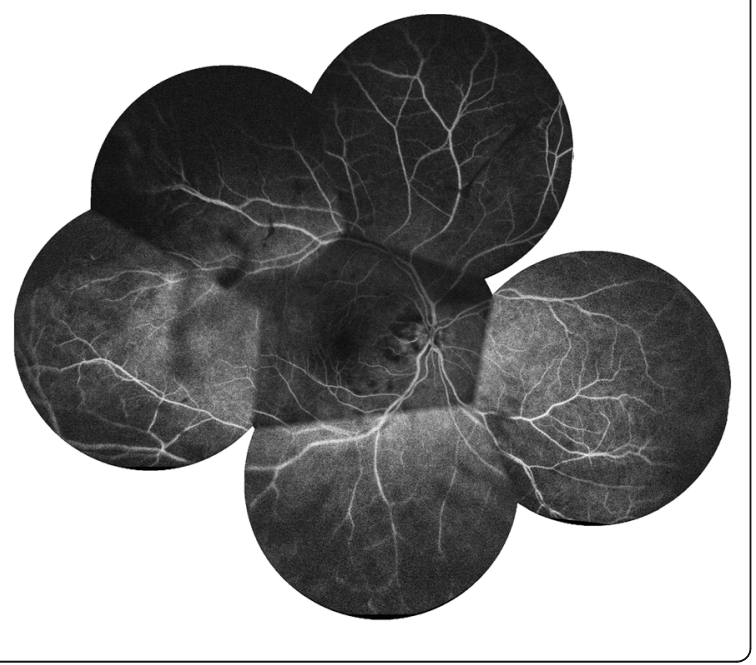

Fig. 2 The patient's left eye fundus and fluorescein angiography. a The color photo of the patient's left eye shows no abnormalities; $\mathbf{b}$. The NIR of the patient's left eye shows multiple lesions appearing as bright, patchy regions in the posterior poles. c. Fluorescein angiography of the left eye showed that the superotemporal retina had a large area of low fluorescence and no abnormal fluorescence was observed

Retinal lesion cryotherapy was performed in RE at 7 days after admission and IOP was still high as about 40 $\mathrm{mmHg}$. Transscleral ciliary body photocoagulation was therefore performed. After the procedure, IOP decreased to $20 \mathrm{mmHg}$. The superotemporal retina nodular lesion was flattened, and the amount of exudates was significantly decreased. The newly formed blood vessels were occluded, and scars could be seen surrounding the lesion (Fig. 3c, d). The patient's condition is stable till the last follow-up.

DNA samples were taken from the family members and tested by NGS and Sanger sequencing verification and revealed that the patient and his father had a novel mutation in the NF1 gene (Fig. 1b, c). This confirmed a final diagnosis of NF1.

\section{Discussion and conclusions}

The formal diagnostic criteria for NF1 were first formulated by the National Institutes of Health Consensus Development Conference in 1987 [3]. The diagnosis of NF1 is now made if a patient has any two of seven listed clinical characteristics summarized by Ferner in 2007 [4]. According to the NF1 diagnostic criteria, the clinical characteristics of this case are consistent with the first criterion ( $\geq 6$ café-au-lait spots) and with the seventh criterion (one of the immediate family members wasaffected). Based on these findings, a clinical diagnosis of NF1 was established. In recent years, some scholars have found that NIR fundus images reveal characteristic changes in NF1 patients. These patients tend to have bright, patchy regions in the posterior pole, with incidence up to $97.5 \%$ (second only to café-au-lait spots, 98\%) [5]. Some pathological studies on NF1 patients [6] also report this change, as well as observations of neural crest-derived melanocytes and nerve cell proliferation in the choroid, which thickens the fundus of the posterior and mid-peripheral regions. Melanocytes are rich in melanin, and the melanin absorbs near-infrared light back-scatter, which appears as bright, patchy regions, scattered across the posterior pole. Some scholars ${ }^{5}$ therefore believe that this change in NIR can be used as a diagnostic criterion for NF1. The NIR findings for our patient and his father both showed this change, which confirmed the clinical diagnosis of NF1.

Common NF1 eye manifestations include congenital glaucoma with ipsilateral upper eyelid plexiform neurofibroma 


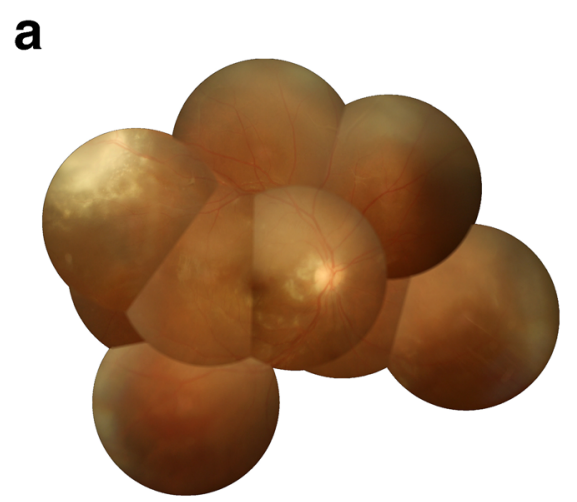

b

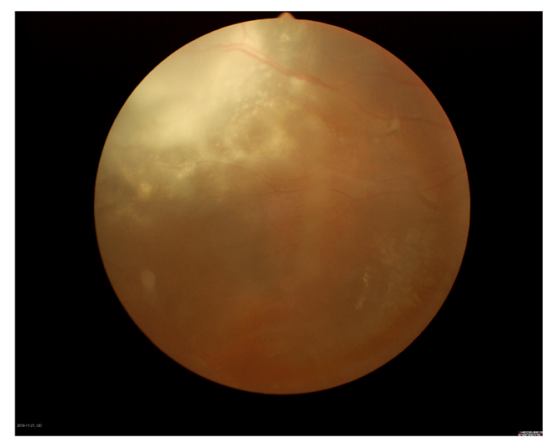

C

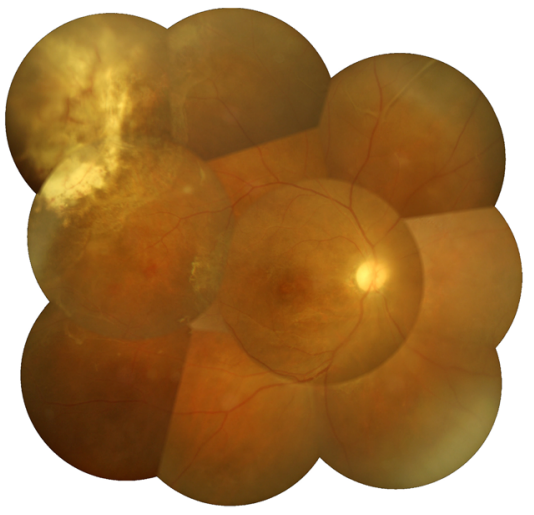

d

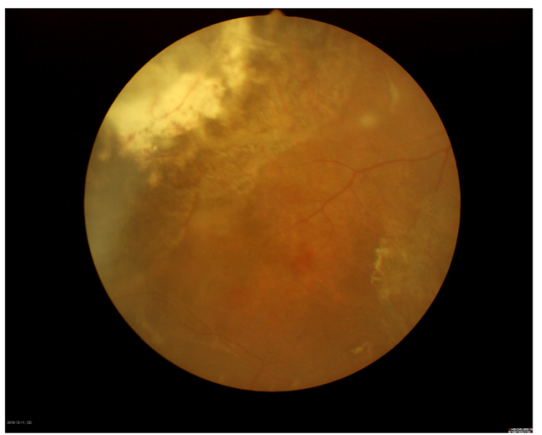

Fig. 3 Changes to retinal lesions in the patient's right eye before and after cryotherapy. a. A color fundus photograph obtained before treatment was administered shows a nodular change in superotemporal retina, gray-white in color, with an unclear boundary; $\mathbf{b}$. A magnified portion of the photograph presented in 4a, showing blood vessels around the lesion; c. A color fundus photograph obtained after treatment shows scar formation in the area of the superotemporal lesion, with a clear boundary; $\mathbf{d}$. A magnified portion of the photograph presented in $4 \mathrm{c}$, showing the disappearance of abnormal blood vessels from the area surrounding the lesion

and ectropion uveae or iris Lisch nodules [7]. In this case, at the time of the initial diagnosis, neovascular glaucoma observed, with iris neovascularization and ectropion uveae, but no iris Lisch nodules, eyelid neurofibroma, or optic glioma. The incidence of neovascular glaucoma in children is very rare; according to reports, NF1 is one possible cause [8]. Studies have shown that mutations in the NF1 gene may lead to the hyperproliferation of perivascular cells and endothelial cells, thereby enhancing the retinal response to ischemia and causing RVPT. RVPT is not a true tumor, but, rather, a reactive lesion of glial cells and blood vessels [9]. The growth of RVPT is driven by elevated levels of vascular endothelial growth factor (VEGF). Some authors report that RVPT secrete VEGF [8]. VEGF plays an important role in the development of new blood vessels. In this case, the patient with NF1 was diagnosed with neovascular glaucoma accompanied by RVPT. After the intravitreal injection of an anti-VEGF agent, in addition with retinal lesion cryotherapy and transscleral ciliary body photocoagulation, the patient's IOP returned to normal, with the RVPT scarring.

Cases of NF1 that begin with neovascular glaucoma accompanied by RVPT are quite rare. So far, only 3 cases have been reported in the literature [8]. We compared characteristics of those three reported cases with those of the patient from the present study. These findings show our case has no systematic involvement, but has genetic evidence and positive family history. Therefore, our diagnosis would be more convincing.

Based on the findings presented above, we suggest that evaluations of young patients with neovascular glaucoma should include careful attention to the overall condition of the patient and his/her parents, as well as family history. If necessary, NF1 molecular testing should be performed to avoid a missed diagnosis or misdiagnosis. In the case we first report one novel mutation in NF1 in association Chinese patients with NF1 without systemic findings, and the result expands the mutation spectrum of NF1.

\section{Abbreviations}

NF1: Neurofibromatosis type 1; RVPT: Retinal vasoproliferative tumor; RE: Right eye; VA: Visual acuity; LE: Left eye; IOP: Intraocular pressure; NIR: Near-infrared reflectance; VEGF: Vascular endothelial growth factor

\section{Acknowledgements} Not Applicable.

Authors' contributions

LS and RL contributed equally to this case report and they were both major contributors in writing the manuscript. QDM contributed to the literature 
research and preparation of the manuscript and Figs. YT and MXH are responsible for the design of the case report and the revision of the manuscript. All authors read and approved the final manuscript.

\section{Funding}

None.

Availability of data and materials

All data are shown in the figures.

\section{Ethics approval and consent to participate}

Ethical approval was not required as this manuscript presents a case study. It was performed in accordance with the tenets of the Declaration of Helsinki.

\section{Consent for publication}

Written informed consent was obtained from the patient and his parents of this case report and any accompanying images.

\section{Competing interests}

The authors declare that they have no competing interests.

Received: 9 September 2019 Accepted: 14 April 2020

Published online: 28 April 2020

\section{References}

1. Williams VC, Lucas J, Babcock MA, Gutmann DH, Korf B, Maria BL Neurofibromatosis type1 revisited. Pediatrics. 2009;123(1):124-133.

2. Barac IR, Pop MD, Gheorghe Al, Taban C. Neovascular secondary glaucoma, etiology and pathogenesis. Romanian J Ophthalmol. 2015;59(1):24.

3. National Institutes of Health Consensus Development Conference Statement. Neurofibromatosis. Bethesda, Md., USA, July 13-15, 1987. Neurofibromatosis. 1988;1(3):172-17.

4. Ferner RE. Neurofibromatosis 1 and neurofibromatosis 2: a twenty first century perspective. Lancet Neurol. 2007;6(4):340-51.

5. Moramarco A, Giustini S, Nofroni I, et al. Near-infrared fundus autofluorescence-visualized melanin in the choroidal abnormalities of neurofibromatosis type 1. Graefes Arch Clin Exp Ophthalmol. 2018;256(2): 307-11.

6. Nakakura S, Shiraki K, Yasunari T, Hayashi Y, Ataka S, Kohno T. Quantification and anatomic distribution of choroidal abnormalities in patients with type I neurofibromatosis. Graefes Arch Clin Exp Ophthalmol. 2005;243(10):980-4.

7. Kinori M, Hodgson N, Zeid JL. Ophthalmic manifestations in neurofibromatosis type 1. Surv Ophthalmol. 2018;63(4):518-33.

8. Al Freihi SH, Edward DP, Nowilaty SR, Abouammoh MA, Morales J. Iris Neovascularization and neovascular glaucoma in neurofibromatosis type 1: report of 3 cases in children. J Glaucoma. 2013;22(4):336-41.

9. Shields JA, Reichstein D, Mashayekhi A, Shields CL. Retinal vasoproliferative tumors in ocular conditions of childhood. J AAPOS. 2012;16(1):6-9.

\section{Publisher's Note}

Springer Nature remains neutral with regard to jurisdictional claims in published maps and institutional affiliations.

Ready to submit your research? Choose BMC and benefit from:
- fast, convenient online submission
- thorough peer review by experienced researchers in your field
- rapid publication on acceptance
- support for research data, including large and complex data types
- gold Open Access which fosters wider collaboration and increased citations
- maximum visibility for your research: over 100M website views per year
At BMC, research is always in progress.
Learn more biomedcentral.com/submissions

